\title{
Los corticoides disminuyen la cantidad de días con odinofagia en pacientes con faringitis aguda
}

\author{
Corticosteroids reduce the number of days with sore throat in patients with acute pharyngitis
}

\section{Objetivo}

Determinar el efecto analgésico de los corticoides en el tratamiento de la odinofagia.

\section{Fuentes de datos \\ Medline (1966 a 2008) Embase (1983 a 2008) y Cochrane Library.}

\section{Diseño y selección de estudios}

Revisión sistemática y metanálisis de estudios controlados aleatorizados que hubieran comparado contra placebo el tratamiento con corticoides sistémicos, en adultos o niños atendidos en forma ambulatoria. Fueron excluidos los estudios que hubieran evaluado pacientes con mononucleosis infecciosa, odinofagia post amigdalectomía, intubación y/o abscesos periamigdalinos.

\section{Medición de resultados principales}

Como resultado principal se estimó la proporción de participantes con resolución completa del dolor a las 24 y 48 horas, y la media del tiempo de comienzo del alivio y resolución completa del dolor.

\section{Resultados principales}

En todos los estudios incluidos, tanto la rama intervención como la rama placebo, recibieron tratamiento antibiótico, según criterios propios para cada trabajo. Los diferentes corticoides utilizados se administraron en dosis equivalentes (betametasona $10 \mathrm{mg}$, dexametasona $8 \mathrm{mg}$, prednisona $60 \mathrm{mg}$ ) por vía oral o intramuscular. El alivio sintomático ocurrió más temprano -un promedio de 6,32 horas antes; IC95\% 9,29 a 3,35- en el grupo asignado a corticoides.

En aquellos pacientes con presencia de exudados amigdalinos, la diferencia fue de 6,2 horas (IC95\% 8,4 a 4); y para aquellos pacientes con causa bacteriana confirmada por cultivo o test rápido de antígeno, de 5,3 horas (IC95\% 2,6 a 8); en ambos casos a favor de corticoides. La tabla 1 resume el efecto de los corticoides sobre la proporción de participantes con resolución completa del dolor a las 24 y 48 horas.

Tabla 1: efecto de los corticoides sobre el número de pacientes que experimentaron alivio completo de los síntomas a las 24 y 48 horas

\begin{tabular}{|c|c|c|c|c|c|c|}
\hline \multirow{2}{*}{$\begin{array}{l}\text { Tiempo de } \\
\text { resolución de los } \\
\text { sintomas }\end{array}$} & \multicolumn{2}{|c|}{ Corticoides } & \multicolumn{2}{|c|}{ Placebo } & \multirow{2}{*}{$\begin{array}{l}\text { RR (IC95\%) } \\
\text { a favor de } \\
\text { corticoides }\end{array}$} & \multirow{2}{*}{ NNT (IC95\%) } \\
\hline & $\begin{array}{c}\text { Pacientes } \\
\text { aliviados (\%) }\end{array}$ & Total & $\begin{array}{c}\text { Pacientes } \\
\text { aliviados (\%) }\end{array}$ & Total & & \\
\hline 24 horas & $54(39 \%)$ & 139 & $18(12 \%)$ & 147 & $3,16(1,97$ a 5,08$)$ & $3,7(2,8$ a 5,9$)$ \\
\hline 48 horas & $74(76 \%)$ & 98 & $52(47 \%)$ & 111 & $1,65(1,32$ a 2,06$)$ & $3,3(2,4$ a 5,6$)$ \\
\hline
\end{tabular}

RR: Riesgo relativo. IC95\%: Intervalo de confianza 95\%. NNT: número necesario de tratar.

\section{Conclusiones}

El uso de corticoides aumenta la proporción de pacientes que presentan alivio sintomático completo dentro de las primeras 24 a 48 horas. Los autores recomiendan el uso de corticoides en pacientes con faringitis con exudado o de causa bacteriana.

Palabras claves: corticoides, faringitis, odinofagia

Keywords: corticosteroids, pharyngitis, sore throat

Fuentes de financiamiento: British Society for Antimicrobial Chemotherapy Systematic Review Grant.

\section{Comentario}

La faringitis aguda es una de las causas más comunes de consulta en atención primaria. En Estados Unidos se estima que es motivo de 200 visitas al médico por cada 1000 personas/año, una tasa que duplica la consulta por cualquier otra causa de enfermedad infecciosa'. El uso de antibióticos en esta infección ha demostrado un efecto modesto sobre el alivio del dolor y la fiebre $^{2,3}$. Por otro lado, el uso de corticoides ha demostrado ser útil en otras infecciones de vía aérea superior ${ }^{4-6}$.

Este estudio demuestra que el uso de corticoides sistémicos en una sola dosis triplica el número de pacientes que experimentan alivio sintomático completo a las 24 horas, con una tendencia superior en aquellos pacientes con faringitis exudativa o de causa bacteriana confirmada.

\section{Conclusiones del comentador}

Los corticoides sistémicos en una dosis son seguros y tienen pocos efectos adversos. Su uso puede ser considerado como tratamiento analgésico en los pacientes con faringitis aguda, especialmente en aquellas de causa bacteriana confirmada o de alta sospecha clínica (tres o más de los siguientes hallazgos: fiebre, adenomegalias regionales sensibles, exudado amigdalino, ausencia de catarro de vía aérea superior). Aún quedaría por confirmar cuál sería la mejor vía de administración?.

Tamara Sigal [ Servicio de Medicina Familiar y Comunitaria del Hospital Italiano de Buenos Aires. tamara.sigal@ hospitalitaliano.org.ar ]

Sigal T. Los corticoides disminuyen la cantidad de días con odinofagia en pacientes con faringitis aguda. Evid Actual Práct Ambul 12(4):129 Oct-Dic 2009. Comentado de: Hayward G. y col. Corticosteroids for pain relief in sore throat: systematic review and meta-analysis. BMJ. 2009;339: b2976. doi: 10.1136/bmj.b2976. PubMed PMID: 19661138.

Disponible libremente en Internet: http://www.ncbi.nlm.nih.gov/pmc/articles/PMC2722696/?tool=pubmed (último acceso: 01/12/09).

\section{Referencias}

1. Bisno A. Acute Pharyngitis. NEJM 2001;344:205-211

2. Del Mar C y col. Antibiotics for sore throat. Cochrane Database Syst Rev 2006;(4):CD000023.

3. NICE Short Clinical Guidelines Technical Team (2008). Respiratory tract infections - antibiotic prescribing. Prescribing of antibiotics for self-limiting respiratory tract infections in adults and children in primary care. London: National Institute for Health and Clinical Excellence.

Disponible en URL: http://www.nice.org.uk/nicemedia/pdf/CG69FullGuideline.pdf (último acceso 22/11/2009).

4. Zalmanovici A y col. Steroids for acute sinusitis. Cochrane Database Syst Rev 2007;(2):CD005149.

5. Russell K y col. Glucocorticoids for croup. Cochrane Database Syst Rev 2004;(1):CD001955.

6. Candy B y col. Steroids for symptom control in infectious mononucleosis. Cochrane Database Syst Rev 2006;3:CD004402.

7. Centor R y col. The diagnosis of strep throat in adults in the emergency room. Med Decis Making 1981;1:239-4 